\title{
Mitochondrial DNA (mtDNA) haplogroups and serum levels of anti-oxidant enzymes in patients with osteoarthritis
}

\author{
Mercedes Fernandez-Moreno' ${ }^{1}$ Angel Soto-Hermida', Sonia Pertega², Natividad Oreiro ${ }^{1}$, Carlos Fernandez-Lopez ${ }^{1}$, \\ Ignacio Rego-Perez ${ }^{1 \dagger}$ and Francisco J Blanco ${ }^{1,3^{*}+}$
}

\begin{abstract}
Background: Oxidative stress play a main role in the initiation and progression of the OA disease and leads to the degeneration of mitochondria. To prevent this, the chondrocytes possess a well-coordinated enzymatic antioxidant system. Besides, the mitochondrial DNA (mtDNA) haplogroups are associated with the OA disease. Thus, the main goal of this work is to assess the incidence of the mtDNA haplogroups on serum levels of two of the main antioxidant enzymes, Manganese Superoxide Dismutase (Mn-SOD or SOD2) and catalase, and to test the suitability of these two proteins for potential OA-related biomarkers.
\end{abstract}

Methods: We analyzed the serum levels of SOD2 and catalase in 73 OA patients and 77 healthy controls carrying the haplogroups J, $U$ and H, by ELISA assay. Knee and hip radiographs were classified according to Kellgren and Lawrence (K/L) scoring from Grade 0 to Grade IV. Appropriate statistical analyses were performed to test the effects of clinical variables, including gender, body mass index (BMI), age, smoking status, diagnosis, haplogroups and radiologic $K / L$ grade on serum levels of these enzymes.

Results: Serum levels of SOD2 appeared statistically increased in OA patients when compared with healthy controls $(p<0.001)$. Even in those OA patients with higher OA severity ( $K / L$ grade $I V)$, the serum levels of this antioxidant enzyme appeared more significantly increased than in OA patients with lower $K / L$ grade $(p<0.001)$. The mtDNA haplogroups showed an influence on serum levels of catalase $(p=0.054)$, being carriers of the mtDNA haplogroup J those who showed higher serum levels than non-J carriers $(p=0.057)$.

Conclusions: The increased levels of SOD2 in OA patients indicate an increased oxidative stress OA-related, therefore this antioxidant enzyme could be a suitable candidate biomarker for diagnosis of OA. Mitochondrial haplogroups significantly correlates with serum levels of catalase

\section{Background}

Osteoarthritis (OA), the most common joint disease and cause of musculoskeletal disability in elderly people, is characterized by late-onset degeneration of articular cartilage, leading to joint destruction and severe impairment of mobility [1]. It is also the main cause of work incapacity and one of the most common reasons for visiting primary physicians. The metabolic and structural changes that take place in the articular cartilage,

\footnotetext{
* Correspondence: fblagar@sergas.es

† Contributed equally

'Osteoarticular and Aging Research Lab. Rheumatology Division. INIBIC-

Hospital Universitario A Coruña. Spain

Full list of author information is available at the end of the article
}

including the oxidative stress, are thought to play a main role in the initiation and progression of this disease.

Actually, OA-related molecular biomarkers are being developed with the aim of detecting the progression of OA with more reliability and sensitivity, preferably early in the disease process $[2,3]$. Because of their greater sensitivity compared with radiographs, several molecular markers for bone, cartilage and synovial have been described as useful for the early identification of OA and of patients at high risk for progression, for monitoring disease progression, and for assessing therapeutic response [3-6]. In this sense, our group has recently

\section{Biomed Central}


added new candidate genetic biomarkers, the mitochondrial DNA (mtDNA) haplogroups, which we suggest can be useful as complementary factors when the classical OA-related molecular biomarkers are analyzed.

The mtDNA haplogroups have been associated not only with several multifactorial diseases [7-9] and ageing $[10,11]$, but also with a lower prevalence and severity of knee and hip OA $[12,13]$. Besides, they modulate the serum levels of some collagen type-II molecular biomarkers [14] as well as some proteolytic enzymes, such as metalloproteinases [15]. The proposed mechanism relies on the different metabolic characteristics of these haplogroups, reflected by the performance of the mitochondrial oxidative phosphorylation system (OXPHOS) of each haplogroup $[7,16]$. The OXPHOS system is a mitochondrial metabolic pathway that uses energy released by the oxidation of nutrients to produce adenosine triphosphate (ATP) as electrons are transferred from electron donors to electron acceptors, such as oxygen, in redox reactions. These redox reactions, carried out by a series of protein complexes within mitochondria, release energy which is used to form ATP.

The different metabolic characteristics make haplogroup J carriers to show not only lower serum levels of catabolic OA-related biomarkers when compared with those carriers of the haplogroup $\mathrm{H}$ [14] but also lower oxygen consumption and lower oxidative damage [17].

As mentioned above, elevated levels of oxidative stress occur in OA and aged cartilage [18]. Although reactive oxygen species (ROS) are involved in the control of various aspects of biological processes in chondrocytes as intracellular second messenger molecules [19], elevated production of ROS leads to i) telomere instability and downregulation of chondrocyte function [20], ii) increased inflammatory response [21], iii) cartilage degradation, by cleaving collagen and aggrecan and activating matrix metalloproteinases (MMPs) [22], and iv) cell death [23]. Oxidative stress also results in the degeneration of mitochondria, the main source of ROS, leading to a leakage of oxidative chain and significant damage to the mitochondrial genome and reduced mtDNA capacity for repair [24].

To prevent an accumulation of ROS-mediated damage, chondrocytes possess a well-coordinated enzymatic antioxidant system formed principally by superoxide dismutases (SODs), catalase and glutathione peroxidase (GPX). SOD2 and SOD3 has been shown to be downregulated in OA cartilage [25-27]; and catalase activity was shown to be increased in OA patients compared with healthy controls [28].

In summary, taking into account the incidence of the oxidative stress in the OA process, as well as the incidence of the mtDNA haplogroups in both the performance of the OXPHOS system and in the OA disease, even on serum levels of classical OA-related molecular biomarkers and proteolytic enzymes, the aim of this work is to perform a retrospective study to evaluate the effects of the mtDNA haplogroups on serum levels of SOD2 and catalase, as well as to test the suitability of these two proteins for potential OA-related biomarkers. The study population is a previously described cohort of OA patients and healthy controls from the north of Spain, consisted in 73 OA subjects and 77 healthy controls carrying the mtDNA haplogroups J, U or $\mathrm{H}$ [14].

\section{Methods}

\section{Subjects}

The population analyzed in this study has been described previously [14]. A total of 73 unrelated patients diagnosed with knee or hip OA (25 carrying haplogroup J, 25 carrying haplogroup $U$ and 23 carrying haplogroup $\mathrm{H}$ ) were included in the present study. Patients meeting the inclusion criteria for this study included individuals of both sexes (52 females; 21 males), older than 41-years-old (mean age: $67.74 \pm 8.96$ years-old; range: 51-95), and diagnosed with OA following the American College of Rheumatology (ACR) criteria [29]. Knee and hip radiographs from 148 subjects were classified according to Kellgren and Lawrence (K/ L) scoring from Grade 0 to Grade IV [30]. Only those joints of OA patients diagnosed with OA were examined for presence of radiographic OA. Of the 77 subjects who met the inclusion criteria for normal subjects, 25 carried haplogroup J, 25 haplogroup $\mathrm{U}$ and 27 haplogroup $\mathrm{H}$. These control subjects included 39 females and 38 males older than 41-years-old (mean age: $66.01 \pm 11.88$ years-old; range: 42-94), who did not meet the ACR criteria for knee or hip OA. In all cases, informed consent and the agreement of the ethical committee from Galician Health Administration were obtained.

\section{mtDNA haplogroups genotyping}

The samples obtained for the study were haplogrouptyped using a previously described assay [12]. Briefly, a multiplex PCR for the amplification of $6 \mathrm{mtDNA}$ fragments that contain 6 informative mtDNA single nucleotide polymorphisms (SNPs) was performed, followed by a single base extension assay (SBE) prior purification of the amplified PCR products. Finally, the fragments were run in an automatic DNA sequencer (ABI 3130XL) to assign the mtDNA haplogroups based on the combination of the informative mtDNA SNPs. For this study, only subjects carrying mtDNA haplogroups J, $\mathrm{H}$ or $\mathrm{U}$ were included.

\section{Molecular biomarkers}

Fasting blood samples were collected from each subject in plain tubes containing separation gel. These were 
allowed to stand for 20 minutes, then centrifuged for 10 minutes at $800 \mathrm{~g}$. The serum was then divided into aliquots and stored at $-80^{\circ} \mathrm{C}$ pending assay.

For this study, the serum levels of two antioxidant enzymes were measured: SOD2 and catalase. They were measured in our facilities using enzyme-linked immunosorbent assays (ELISAs) according to the manufacturer's recommendations. Serum SOD2 levels were measured using a kit from ABfrontier (Republic of Korea) and catalase was measured using a Camel catalase ELISA kit from Cusabio Biotech (Wuhan, China).

Determination of the serum levels of these enzymes was performed by simultaneously assaying OA patients and healthy controls, regardless of the mtDNA haplogroup.

\section{Statistical analysis}

Statistical analyses were performed using SPSS software, release 17 (Chicago, USA). In univariate analysis, a nonparametric study was performed utilizing the MannWhitney $U$-test to compare serum molecular marker concentrations between OA patients and healthy controls. The Kruskal-Wallis test was used to compare molecular marker concentrations among the three haplogroups ( $\mathrm{J}, \mathrm{U}$ and $\mathrm{H}$ ) regardless of the diagnosis. To look for possible correlations among the two enzymes analyzed, a correlation analysis using Spearmans Rho was used. In all cases, the Bonferroni correction for multiple comparisons was applied. Thus, p-values were obtained after multiplying the number of outcomes tested by the number of haplogroups $(\mathrm{k}=2 \times 3)$.

Following these preliminary analyses, an analysis of covariance (ANCOVA) was used to evaluate the effects on enzyme serum levels (dependent variable) of each of the haplogroups as well as diagnosis, adjusting for the confounder effects of gender, body mass index (BMI), smoking status and age. When a significant effect was found either in haplogroups or in diagnosis, the conservative Bonferroni post hoc multiple comparisons test was performed to compare group means. If the interaction between diagnosis and haplogroup was statistically significant main effects should not be interpreted, so differences among the $2 \times 3=6$ possible combinations of diagnosis (OA and healthy control) and haplogroups $(\mathrm{H}, \mathrm{J}$ and $\mathrm{U})$ were analyzed by using the same Bonferroni post hoc multiple comparisons test. Before the multivariate analysis, a distribution analysis using the Kolmogorov-Smirnov test showed that the both SOD2 and catalase were not normally distributed; therefore, their concentrations were square and log transformed respectively to obtain a normal distribution. Model diagnostic statistics were also analysed using residual plots.

The influence of radiographic grade to the serum levels of the molecular markers was tested using the non-parametric Jonckheere-Terpstra test for ordered groups. For this approach we obtained the radiographic grade of 148 subjects out of the 150 that are part of the study. Using K/L scores, subjects were divided into three radiographic groups: group A included 77 healthy controls (K/L grade 0 and grade $\mathrm{I}$ ), group $\mathrm{B}$ consisted of 47 OA patients with $\mathrm{K} / \mathrm{L}$ grades II and III, and group C included $24 \mathrm{OA}$ patients with $\mathrm{K} / \mathrm{L}$ grade IV.

\section{Results}

Non-parametric analysis of serum levels of the molecular markers

We first compared the serum levels of the enzymes assayed between OA patients and healthy controls. The results showed that levels of SOD2 were significantly increased in OA patients $(\mathrm{p}<0.001)$ (Table 1$)$. Serum levels of catalase showed a non significant trend toward increased values in OA patients, compared to healthy controls (Table 1).

Interestingly, the haplogroups have a significant influence on serum levels of catalase regardless of diagnosis, so that carriers of haplogroup J showed higher levels of catalase $(p=0.054)$. Regarding to SOD2, the results did not reach the statistical significance, but a trend toward decreased serum levels in carriers of haplogroup $\mathrm{H}$ compared with non-H carriers was detected (Table 2).

When we compared the three groups based on the K/ L score, only SOD2 showed a significant trend towards proportionally higher serum levels in both groups B (K/ $\mathrm{L}$ grade II and III) and $\mathrm{C}(\mathrm{K} / \mathrm{L}$ grade IV) than in group

Table 1 Serum levels of molecular markers in healthy controls and osteoarthritis (OA) patients

\begin{tabular}{|c|c|c|c|c|c|}
\hline \multirow[b]{2}{*}{ Markers } & \multicolumn{2}{|c|}{$\begin{array}{l}\text { Healthy controls } \\
\quad(n=77)\end{array}$} & \multicolumn{2}{|c|}{$O A(n=73)$} & \multirow[b]{2}{*}{$\mathrm{p}^{*}$} \\
\hline & Mean (SD) & Median & Mean (SD) & Median & \\
\hline $\begin{array}{c}\text { SOD2 } \\
(\mathrm{ng} / \mathrm{mL})\end{array}$ & $20.83(30.81)$ & 13.50 & $36.38(11.16)$ & 36.41 & $<0.001^{* *}$ \\
\hline $\begin{array}{l}\text { Catalase } \\
(\mathrm{ng} / \mathrm{mL})\end{array}$ & $14.50(27.68)$ & 5.03 & $21.88(40.94)$ & 8.00 & 0.189 \\
\hline
\end{tabular}

$(*)$ Mann-Whitney non-parametric $U$-test

$(* *)$ indicates statistical significance alter Bonferroni correction $(p \leq 0.05)$

SD $=$ Standard deviation 
Table 2 Serum levels of molecular markers in the mitochondrial DNA (mtDNA) haplogroups $\mathbf{H}, \mathbf{U}$ and $\mathbf{J}$

\begin{tabular}{cccccccc}
\hline & \multicolumn{2}{c}{ Haplogroup $\mathbf{H}(\mathbf{n}=\mathbf{5 0})$} & \multicolumn{2}{c}{ Haplogroup $\mathbf{U}(\mathbf{n}=\mathbf{5 0})$} & \multicolumn{2}{c}{ Haplogroup J $(\mathbf{n}=\mathbf{5 0})$} \\
\hline Markers & Mean $(\mathrm{SD})$ & Median & Mean (SD) & Median & Mean (SD) & Median & $\mathbf{p}^{*}$ \\
\hline SOD2 $(\mathrm{ng} / \mathrm{mL})$ & $23.27(13.92)$ & 24.88 & $31.34(34.52)$ & 26.29 & $30.70(19.60)$ & 30.68 & 0.149 \\
Catalase $(\mathrm{ng} / \mathrm{mL})$ & $21.20(37.49)$ & 5.22 & $8.37(11.34)$ & 4.37 & $25.14(45.42)$ & 8.57 & $\mathbf{0 . 0 5 4}$ \\
\hline
\end{tabular}

(*) Kruskal-Wallis non-parametric test

$(* *)$ indicates statistical significance alter Bonferroni correction $(p \leq 0.05)$

$\mathrm{SD}=$ Standard deviation

A $(\mathrm{K} / \mathrm{L}$ grade 0 and $\mathrm{I})(\mathrm{p}<0.001)($ Table 3$)$. Finally, no significant correlations among the serum levels of these two enzymes were detected.

\section{Multiple regression analysis}

We then performed a multiple regression analysis to assess the effects of the mtDNA haplogroups and clinical variables including gender, age, BMI, smoking status and diagnosis on the serum levels of the enzymes analyzed.

The results obtained for SOD2 showed that serum levels of this antioxidant enzyme were significantly increased in OA patients compared to healthy controls $(\mathrm{p}<0.001)$. On the contrary, no significant influence of the mtDNA haplogroups neither significant interactions between mtDNA haplogroups and diagnosis were detected (Table 4).

The results of the multiple regression analysis for catalase showed that serum levels were slightly modulated by the mtDNA haplogroup J, bordering on the statistical significance, so that carriers of this haplogroup have higher levels than non carriers $(p=0.057)($ Table 4$)$. On the contrary, carriers of the mtDNA haplogroup $U$ showed a non-significant trend towards lower levels of catalase than non-U carriers $(\mathrm{p}=0.075)$ (Table 4). However, as described for SOD2, no significant interactions between mtDNA haplogroups and diagnosis were found.

\section{Discussion}

In this study we analyzed whether some biomarkers related to the oxidative stress are modulated by the mtDNA haplogroups in the context of the OA disease. The choice of the mtDNA haplogroups $J$ and $U$ was due to their role in the prevalence and severity of knee and hip OA $[12,13]$; the mtDNA haplogroup $H$ was also selected because is the most frequent mtDNA haplogroup in European populations [31].

Both SOD2 and catalase are two of the main members of the well-coordinated enzymatic antioxidant system in chondrocytes since ROS are, besides matrix metalloproteinases, the main biochemical factors of cartilage degradation [32]. Briefly, SOD2 catalyses the dismutation of superoxide anion $\left(\mathrm{O}_{2}{ }^{-}\right)$to oxygen $\left(\mathrm{O}_{2}\right)$ and hydrogen peroxide $\left(\mathrm{H}_{2} \mathrm{O}_{2}\right)$, and this $\mathrm{H}_{2} \mathrm{O}_{2}$ in turn is eliminated by catalase, the most efficient enzyme for the degradation of $\mathrm{H}_{2} \mathrm{O}_{2}$, or by glutathione peroxidase. An imbalance in this coordinated system will lead to the increased oxidative stress that takes place in the OA disease.

mtDNA haplogroups have been described to be involved in the development of the OA disease [12,13],

Table 3 Demographics of the study population and serum levels of enzyme markers grouped by radiological severity (Kellgren/Lawrence Score) and distribution of the haplogroups $\mathbf{H}, \mathbf{U}$ and $\mathbf{J}$ in the $\mathbf{3}$ radiographic groups

\begin{tabular}{|c|c|c|c|c|c|c|c|c|}
\hline & \multicolumn{2}{|c|}{ Healthy controls $(n=77)$} & \multicolumn{4}{|c|}{ OA patients $(n=73)$} & & \\
\hline Mean age (range) & \multicolumn{2}{|c|}{66.01 years-old (42-94) } & \multicolumn{4}{|c|}{67.74 years-old (51-95) } & & \\
\hline Females/Males & \multicolumn{2}{|c|}{39 females/38 males } & \multicolumn{4}{|c|}{52 females/21 males } & & \\
\hline Haplogroups & \multicolumn{2}{|c|}{$\begin{array}{l}\text { Group } \mathbf{A}(\mathbf{n}=\mathbf{7 7}) \\
K / L \text { grade } 0 \text { and I }\end{array}$} & \multicolumn{2}{|c|}{$\begin{array}{l}\text { Group } B(n=47) \\
K / L \text { grade } \| \text { and III }\end{array}$} & \multicolumn{2}{|c|}{$\begin{array}{c}\text { Group } C(n=24) \\
\text { KLL grade IV }\end{array}$} & & \\
\hline Haplogroup H, n(\%) & \multicolumn{2}{|c|}{$25(32.5)$} & \multicolumn{2}{|c|}{$18(38.3)$} & \multicolumn{2}{|c|}{$7(29.2)$} & & \\
\hline Haplogroup U, n(\%) & \multicolumn{2}{|c|}{$25(32.5)$} & \multicolumn{2}{|c|}{$12(25.5)$} & \multicolumn{2}{|c|}{$13(54.2)$} & & \\
\hline Haplogroup J, n(\%) & \multicolumn{2}{|c|}{$27(35)$} & \multicolumn{2}{|c|}{$17(36.2)$} & \multicolumn{2}{|c|}{$4(16.7)$} & & \\
\hline Markers & Mean (SD) & Median & Mean (SD) & Median & Mean (SD) & Median & J-T & $\mathrm{p}^{*}$ \\
\hline SOD2 (ng/mL) & $20.83(30.81)$ & 13.50 & $35.75(10.44)$ & 35.02 & $38.10(12.74)$ & 39.23 & 7.796 & $<0.001 * *$ \\
\hline Catalase (ng/mL) & $14.50(27.68)$ & 5.03 & $22.82(42.49)$ & 8.56 & $20.58(38.87)$ & 8.00 & 1.227 & 0.220 \\
\hline
\end{tabular}

Group A: K/L grade 0 and I; Group B: K/L grade II and III; Group C: K/L grade IV

(*) Jonckheere-Terstra (J-T) non-parametric test

$\mathrm{J}-\mathrm{T}=$ established $\mathrm{J}$-T statistic

$(* *)$ indicates statistical significance after Bonferroni correction $(p \leq 0.05)$

SD $=$ Standard deviation 
Table $4 p$ values from the ANOVA table for the analysis of covariance of serum levels of the two enzymes analyzed

\begin{tabular}{ccc}
\hline Variable & SOD2 & Catalase \\
\hline Gender & 0.422 & 0.536 \\
Age & 0.800 & 0.211 \\
BMl & 0.655 & 0.471 \\
Smoking status & 0.785 & 0.084 \\
Diagnosis & $<\mathbf{0 . 0 0 1 *}$ & 0.249 \\
Haplogroups: & & \\
Haplogroup H (vs non-H) & 0.133 & 0.894 \\
Haplogroup J (vs non-J) & 0.580 & $\mathbf{0 . 0 5 7 *}$ \\
Haplogroup U (vs non-U) & 0.354 & 0.075 \\
Diagnosis X Haplogroup & 0.488 & 0.883 \\
\hline
\end{tabular}

(*) indicates statistical significance $(p \leq 0.05)$

as well as in the modulation of the serum levels of classical collagen type-II molecular biomarkers [14] and proteolytic enzymes [15], probably due to their different OXHPOS performance $[7,16]$ and the differences in the oxidative damage and oxygen consumption among them [17]. These particular characteristics make that some of these haplogroups show a lower ROS production and apoptosis [33,34], hence their involvement on serum levels of certain antioxidant proteins is a matter of relevance.

The results obtained in this work showed that SOD2 was significantly increased in OA patients, even those OA patients with higher radiographic grade showed the highest values too; meanwhile catalase showed a trend toward higher levels in the OA group, but did not reach the statistical significance. The results obtained also showed a influence of the mtDNA haplogroups on serum levels of catalase, so that those carriers of the mtDNA haplogroup J showed higher levels of catalase than non-J carriers regardless of diagnosis.

Despite some authors showed a downregulation of SOD2 in OA cartilage $[27,35]$, the increased serum levels of this enzyme in OA patients showed in this work reflect an increased oxidative stress OA-related, as described by other authors [36]; besides, the deleterious effects of increased SOD2 have been supported in various studies [37]. However, serum levels of catalase were non-significantly increased in OA patients, notwithstanding the fact that catalase has greater stability than SOD2 [28,32]; on the contrary, catalase was increased in carriers of haplogroup J, showing a different pattern than for SOD2.

Despite the influence of the haplogorup J on serum levels of catalase, the potential role of the mtDNA haplogroups on serum levels of these two antioxidant enzymes seems slight, contrarily to the observed in both collagen type II biomarkers and proteolytic enzymes
$[14,15]$. Hence, a future approach will be to analyze the serum levels of these two antioxidant enzymes in a prospective larger cohort of samples to ascertain their increased serum levels in OA patients and therefore to validate their suitability as candidate OA biomarkers, and even their modulation by the mtDNA haplogroups.

Attending to the "BIPED" (Burden of disease, Investigative, Prognostic, Efficacy of intervention and Diagnostic) biomarker classification [38], SOD2 could be considered as a diagnostic marker pending validation, and also a burden of disease marker since, as shown in this study, its serum levels are significantly different attending to the $\mathrm{K} / \mathrm{L}$ score. Regarding to the mtDNA haplogroups, they could be considered as investigative markers because, although their combination with some of the OA-related biomarkers seems to influence their behaviour, to increase information and replicate the findings to allow inclusion into one of the existing categories is still necessary. Otherwise, because we did not find significant differences in serum levels of catalase between OA patients and healthy controls, we consider this potential biomarker as another investigative one.

Biochemical markers of cartilage degradation have received much attention in comparison with others; overall, uCTX-II and sCOMP had the best performance of all currently biochemical markers, they were investigated most frequently and broadly, and scored in the higher ranges of scores form most "BIPED" categories; however, none of the current biochemical markers is sufficiently discriminating to aid diagnosis and/or prognosis of OA, attending to a systematic review carried out by Spil van and collaborators [39].

This study show some limitations that must be considered. This is a retrospective study in which the selection of the samples was based on the availability of serum samples carrying the mtDNA haplogroups J, U or $\mathrm{H}$ with no criterion when obtaining the serum samples; in this sense, it must be pointed out that, for serological analysis, the standardization of sample collection may improve biochemical marker performance since diurnal rhythms and influences of exercise have been described for several biochemical markers [40,41]; besides, repeated thawing and freezing must be avoided in order to obtain reliable results. Otherwise, the sample size may be small when multiple analysis are performed, and specially if we compare with larger GWAS studies, although this work is not. Hence, more samples must be analyzed to replicate these findings, and therefore we have initiated a new prospective collection of samples to try to replicate the findings showed in this study.

\section{Conclusions}

To our knowledge, this is the first work that correlates the serum levels of these enzymes with the mtDNA 
haplogroups in the context of the OA disease. In summary, this work highlights the significantly increased serum levels of SOD2, an important antioxidant enzyme, in OA patients, demonstrating the existence of oxidative stress. Besides, serum levels of catalase are slightly increased in carriers of the mtDNA haplogroup J, when compared with non-J carriers. As described for both type II collagen biomarkers and some proteolytic enzymes OA-related, the influence of the haplogroups on the serum levels of catalase could arise from the different metabolic characteristics of these mitochondrial variants, that make some of them showed a different performance of the OXPHOS system $[7,16]$. Similarly, since serum levels of SOD2 are significantly decreased in healthy controls and significantly increased in OA patients with K/L grade IV, the use of SOD2 as a candidate biomarker for diagnosis of OA is proposed. However, a new prospective study must be performed in order to replicate these findings.

\section{Acknowledgements}

This study was supported by grants from Fundación Española de Reumatologia (programa GEN-SER) and from Fondo Investigación Sanitaria (CIBER-CB06/01/0040)-Spain, Fondo Investigacion Sanitaria-PI 08/2028 Ministerio Ciencia en Innovacion PLE2009-0144, with participation of funds from FEDER (European Community). Ignacio Rego was supported by Contrato de Apoyo a la Investigación-Fondo Investigación Sanitaria (CA10/ 01564).

\section{Author details}

${ }^{1}$ Osteoarticular and Aging Research Lab. Rheumatology Division. INIBICHospital Universitario A Coruña. Spain. ${ }^{2}$ Epidemiology Unit, INIBIC-Hospital Universitario A Coruña. Spain. ${ }^{3}$ CIBER-BBN. ISCIII, Spain.

\section{Authors' contributions}

MFM carried out the experimental procedures of the mitochondrial haplogroups identification. She helped to draft the manuscript and he has given final approval of the version to be published. ASH carried out the quantification of SOD-2 and catalase by ELISA. SP performed the statistical analysis and helped to draft the manuscript. NO and CFL collected the samples and checked clinical histories for the inclusion and exclusion criteria. IRP has been involved in the conception and design of the study, he helped to draft the manuscript and he has given final approval of the version to be published. He was also involved in the mitochondrial haplogroups identification. FJB conceived the study, and participated in its design and coordination and helped to draft the manuscript. All authors read and approved the final manuscript.

\section{Competing interests}

The authors declare that they have no competing interests.

Received: 2 June 2011 Accepted: 22 November 2011 Published: 22 November 2011

\section{References}

1. Felson DT, Zhang Y: An update on the epidemiology of knee and hip osteoarthritis with a view to prevention. Arthritis Rheum 1998, 41(8):1343-1355.

2. Garnero P, Piperno M, Gineyts E, Christgau S, Delmas PD, Vignon E: Cross sectional evaluation of biochemical markers of bone, cartilage, and synovial tissue metabolism in patients with knee osteoarthritis: relations with disease activity and joint damage. Ann Rheum Dis 2001, 60(6):619-626.
3. Garnero P, Ayral X, Rousseau JC, Christgau S, Sandell L, Dougados M, Delmas PD: Uncoupling of type II collagen synthesis and degradation predicts progression of joint damage in patients with knee osteoarthritis. Arthritis Rheum 2002, 46(10):2613-2624.

4. Christgau S, Garnero P, Fledelius C, Moniz C, Ensig M, Gineyts E, Rosenquist C, Qvist P: Collagen type II C-telopeptide fragments as an index of cartilage degradation. Bone 2001, 29(3):209-215.

5. Schett G, Zwerina J, Axmann R, Willeit J, Stefan K: Risk prediction for severe osteoarthritis. Ann Rheum Dis England 2010, 69:1573-1574.

6. Qvist P, Christiansen C, Karsdal MA, Madsen SH, Sondergaard BC, BayJensen AC: Application of biochemical markers in development of drugs for treatment of osteoarthritis. Biomarkers 2010, 15(1):1-19.

7. Ruiz-Pesini E, Lapeña AC, Díez-Sánchez C, Pérez-Martos A, Montoya J, Alvarez E, Díaz M, Urriés A, Montoro L, López-Pérez MJ, et al: Human mtDNA haplogroups associated with high or reduced spermatozoa motility. Am J Hum Genet 2000, 67(3):682-696.

8. van der Walt JM, Dementieva YA, Martin ER, Scott WK, Nicodemus KK, Kroner CC, Welsh-Bohmer KA, Saunders AM, Roses AD, Small GW, et al: Analysis of European mitochondrial haplogroups with Alzheimer disease risk. Neurosci Lett 2004, 365(1):28-32.

9. Lakatos A, Derbeneva O, Younes D, Keator D, Bakken T, Lvova M, Brandon M, Guffanti G, Reglodi D, Saykin A, et al: Association between mitochondrial DNA variations and Alzheimer's disease in the ADNI cohort. Neurobiol Aging 2010, 31(8):1355-1363.

10. Niemi AK, Hervonen A, Hurme M, Karhunen PJ, Jylha M, Majamaa K. Mitochondrial DNA polymorphisms associated with longevity in a Finnish population. Hum Genet 2003, 112(1):29-33.

11. Domínguez-Garrido E, Martínez-Redondo D, Martín-Ruiz C, Gómez-Durán A, Ruiz-Pesini E, Madero P, Tamparillas M, Montoya J, von Zglinicki T, DíezSánchez $C$, et al: Association of mitochondrial haplogroup $J$ and mtDNA oxidative damage in two different North Spain elderly populations. Biogerontology 2009, 10(4):435-442.

12. Rego-Perez I, Fernandez-Moreno M, Fernandez-Lopez C, Arenas J, Blanco FJ: Mitochondrial DNA haplogroups: role in the prevalence and severity of knee osteoarthritis. Arthritis Rheum 2008, 58(8):2387-2396.

13. Rego I, Fernández-Moreno M, Fernández-López C, Gómez-Reino JJ, González A, Arenas J, Blanco FJ: Role of European mitochondrial DNA haplogroups in the prevalence of hip osteoarthritis in Galicia, Northern Spain. Ann Rheum Dis 2010, 69(1):210-213.

14. Rego-Pérez I, Fernández-Moreno M, Deberg M, Pértega S, FenándezLópez C, Oreiro N, Henrotin Y, Blanco FJ: Mitochondrial DNA haplogroups modulate the serum levels of biomarkers in patients with osteoarthritis. Ann Rheum Dis 2010, 69(5):910-917.

15. Rego-Perez I, Fernandez-Moreno M, Deberg M, Pertega S, FernandezLopez C, Oreiro N, Henrotin Y, Blanco FJ: Mitochondrial DNA haplogroups and serum levels of proteolytic enzymes in patients with osteoarthritis. Ann Rheum Dis England 2011, 70:646-652.

16. Gómez-Durán A, Pacheu-Grau D, López-Gallardo E, Díez-Sánchez C, Montoya J, López-Pérez MJ, Ruiz-Pesini E: Unmasking the causes of multifactorial disorders: OXPHOS differences between mitochondrial haplogroups. Hum Mol Genet 2010, 19(17):3343-3353.

17. Martínez-Redondo D, Marcuello A, Casajús JA, Ara I, Dahmani Y, Montoya J, Ruiz-Pesini E, López-Pérez MJ, Díez-Sánchez C: Human mitochondrial haplogroup $\mathrm{H}$ : the highest $\mathrm{VO} 2 \mathrm{max}$ consumer-is it a paradox? Mitochondrion 2010, 10(2):102-107.

18. Henrotin $Y$, Kurz B, Aigner T: Oxygen and reactive oxygen species in cartilage degradation: friends or foes? Osteoarthritis Cartilage, England 2005, 13:643-654.

19. Henrotin YE, Bruckner P, Pujol JP: The role of reactive oxygen species in homeostasis and degradation of cartilage. Osteoarthritis Cartilage, England 2003, 11:747-755.

20. Yudoh K, Nguyen T, Nakamura H, Hongo-Masuko K, Kato T, Nishioka K: Potential involvement of oxidative stress in cartilage senescence and development of osteoarthritis: oxidative stress induces chondrocyte telomere instability and downregulation of chondrocyte function. Arthritis Res Ther 2005, 7(2):R380-391.

21. Cillero-Pastor B, Carames B, Lires-Dean M, Vaamonde-Garcia C, Blanco FJ, Lopez-Armada MJ: Mitochondrial dysfunction activates cyclooxygenase 2 expression in cultured normal human chondrocytes. Arthritis Rheum 2008, 58(8):2409-2419. 
22. Petersen SV, Oury TD, Ostergaard L, Valnickova Z, Wegrzyn J, Thogersen IB, Jacobsen C, Bowler RP, Fattman CL, Crapo JD, et al: Extracellular superoxide dismutase (EC-SOD) binds to type i collagen and protects against oxidative fragmentation. J Biol Chem, United States 2004, 279:13705-13710.

23. Henrotin Y, Kurz B: Antioxidant to treat osteoarthritis: dream or reality? Curr Drug Targets 2007, 8(2):347-357.

24. Grishko VI, Ho R, Wilson GL, Pearsall AW: Diminished mitochondrial DNA integrity and repair capacity in OA chondrocytes. Osteoarthritis Cartilage 2009, 17(1):107-113.

25. Regan E, Flannelly J, Bowler R, Tran K, Nicks M, Carbone BD, Glueck D, Heijnen H, Mason R, Crapo J: Extracellular superoxide dismutase and oxidant damage in osteoarthritis. Arthritis Rheum 2005, 52(11):3479-3491.

26. Aigner T, Fundel K, Saas J, Gebhard PM, Haag J, Weiss T, Zien A, Obermayr F, Zimmer R, Bartnik E: Large-scale gene expression profiling reveals major pathogenetic pathways of cartilage degeneration in osteoarthritis. Arthritis Rheum 2006, 54(11):3533-3544.

27. Ruiz-Romero C, Calamia V, Mateos J, Carreira V, Martinez-Gomariz M, Fernandez M, Blanco FJ: Mitochondrial dysregulation of osteoarthritic human articular chondrocytes analyzed by proteomics: a decrease in mitochondrial superoxide dismutase points to a redox imbalance. Mol Cell Proteomics 2009, 8(1):172-189.

28. Olszewska-Slonina DM, Matewski D, Drewa G, Wozniak A, Czajkowski R, Rajewski P, Olszewski KJ, Zegarska B: Oxidative equilibrium in the prophylaxis of degenerative joint changes: an analysis of pre- and postoperative activity of antioxidant enzymes in patients with hip and knee osteoarthritis. Med Sci Monit, Poland 2010, 16:CR238-245.

29. Altman R, Asch E, Bloch D, Bole G, Borenstein D, Brandt K, Christy W, Cooke TD, Greenwald R, Hochberg M, et al: Development of criteria for the classification and reporting of osteoarthritis. Classification of osteoarthritis of the knee. Diagnostic and Therapeutic Criteria Committee of the American Rheumatism Association. Arthritis Rheum 1986, 29(8):1039-1049.

30. Kellgren JH, Lawrence JS: Radiological assessment of osteo-arthrosis. Ann Rheum Dis 1957, 16(4):494-502.

31. Torroni A, Huoponen K, Francalacci P, Petrozzi M, Morelli L, Scozzari R, Obinu D, Savontaus ML, Wallace DC: Classification of European mtDNAs from an analysis of three European populations. Genetics 1996, 144(4):1835-1850.

32. Mathy-Hartert M, Hogge L, Sanchez C, Deby-Dupont G, Crielaard JM, Henrotin Y: Interleukin-1 beta and interleukin-6 disturb the antioxidant enzyme system in bovine chondrocytes: a possible explanation for oxidative stress generation. Osteoarthritis Cartilage, England 2008, 16:756-763.

33. Wallace DC, Ruiz-Pesini E, Mishmar D: mtDNA variation, climatic adaptation, degenerative diseases, and longevity. Cold Spring Harb Symp Quant Biol 2003, 68:479-486.

34. Ruiz-Pesini E, Mishmar D, Brandon M, Procaccio V, Wallace DC: Effects of purifying and adaptive selection on regional variation in human mtDNA. Science 2004, 303(5655):223-226.

35. Scott JL, Gabrielides C, Davidson RK, Swingler TE, Clark IM, Wallis GA, BootHandford RP, Kirkwood TB, Taylor RW, Young DA: Superoxide dismutase downregulation in osteoarthritis progression and end-stage disease. Ann Rheum Dis, England 2010, 69:1502-1510.

36. Pinto S, Rao AV, Rao A: Lipid peroxidation erythrocyte antioxidants and plasma antioxidants in osteoarthritis before and after homeopathic treatment. Homeopathy Scotland 2008, 97:185-189.

37. Zhong W, Oberley LW, Oberley TD, Yan T, Domann FE, St Clair DK: Inhibition of cell growth and sensitization to oxidative damage by overexpression of manganese superoxide dismutase in rat glioma cells. Cell Growth Differ 1996, 7(9):1175-1186.

38. Bauer DC, Hunter DJ, Abramson SB, Attur M, Corr M, Felson D, Heinegård D, Jordan JM, Kepler TB, Lane NE, et al: Classification of osteoarthritis biomarkers: a proposed approach. Osteoarthritis Cartilage 2006, 14(8):723-727.

39. van Spil WE, DeGroot J, Lems WF, Oostveen JC, Lafeber FP: Serum and urinary biochemical markers for knee and hip-osteoarthritis: a systematic review applying the consensus BIPED criteria. Osteoarthritis Cartilage 2010, 18(5):605-612.

40. Andersson ML, Thorstensson CA, Roos EM, Petersson IF, Heinegård D, Saxne T: Serum levels of cartilage oligomeric matrix protein (COMP) increase temporarily after physical exercise in patients with knee osteoarthritis. BMC Musculoskelet Disord 2006, 7:98.

41. Kong SY, Stabler TV, Criscione LG, Elliott AL, Jordan JM, Kraus VB: Diurnal variation of serum and urine biomarkers in patients with radiographic knee osteoarthritis. Arthritis Rheum 2006, 54(8):2496-2504.

\section{Pre-publication history}

The pre-publication history for this paper can be accessed here: http://www.biomedcentral.com/1471-2474/12/264/prepub

doi:10.1186/1471-2474-12-264

Cite this article as: Fernandez-Moreno et al: Mitochondrial DNA (mtDNA) haplogroups and serum levels of anti-oxidant enzymes in patients with osteoarthritis. BMC Musculoskeletal Disorders 2011 12:264.

\section{Submit your next manuscript to BioMed Central and take full advantage of:}

- Convenient online submission

- Thorough peer review

- No space constraints or color figure charges

- Immediate publication on acceptance

- Inclusion in PubMed, CAS, Scopus and Google Scholar

- Research which is freely available for redistribution

Submit your manuscript at www biomedcentral com/submit
C Biomed Central 